\title{
Increased Adrenal Sensitivity to Angiotensin II in Low-Renin Essential Hypertension
}

\author{
Max Wisgerhof and Ronald D. Brown, Endocrine Research Unit, Department \\ of Internal Medicine, Mayo Clinic and Mayo Foundation, Rochester, \\ Minnesota 55901
}

A B S T RAC T Studies were undertaken to determine if the dissociation of aldosterone and plasma renin activity in low-renin essential hypertension is due to altered adrenal responsiveness to angiotensin II. The responsiveness of the adrenal glands to angiotensin II was determined by infusing graded doses of angiotensin II into normal subjects and into patients with essential hypertension and measuring changes in levels of plasma aldosterone in response to the infusion. To minimize the influence of endogenous angiotensin II and ACTH, supplemental sodium and dexamethasone were given before the infusions. Levels of plasma aldosterone and plasma renin activity were determined in normal subjects and in the same patients after the combined stimuli of furosemide and upright posture, a maneuver used to increase the level of endogenous angiotensin II. To determine if the changes in levels of plasma aldosterone during infusion of angiotensin II were due to alteration of the metabolic clearance of aldosterone, the metabolic clearance of aldosterone was measured before and during the infusion of angiotensin II.

After sodium loading, dexamethasone treatment, and supine posture, levels of plasma aldosterone of normal subjects and patients with essential hypertension were suppressed equally. In response to the infusion of angiotensin II, the levels of plasma aldosterone of patients with low-renin essential hypertension were significantly higher than those of normal subjects or of patients with normal-renin essential hypertension.

This work was presented in part at the meeting of the Southern Section of the American Federation for Clinical Research, New Orleans, La. 27 January 1977, and at the 59th Annual Meeting of the Endocrine Society, Chicago, Ill. 9 June 1977.

Dr. Wisgerhof was supported in part by a Research Fellowship Award, 5F32 HL-5270, from the National Institutes of Health, U. S. Public Health Service, and by the Mayo Foundation.

Received for publication 18 July 1978 and in revised form 9 December 1978.
After furosemide and upright posture, levels of plasma aldosterone of patients with low-renin essential hypertension were significantly higher than those of patients with normal-renin essential hypertension, despite a blunted response in plasma renin activity of the patients with low-renin essential hypertension. Decreases in metabolic clearance of aldosterone during infusion of angiotensin II were similar in patients with normalrenin essential hypertension and in patients with lowrenin essential hypertension and accounted for only a small fraction of the marked increase in levels of plasma aldosterone of patients with low-renin essential hypertension. It is concluded that patients with lowrenin essential hypertension have increased adrenal sensitivity to angiotensin II. This increased sensitivity may explain the dissociation of aldosterone and plasma renin activity in low-renin essential hypertension.

\section{INTRODUCTION}

The regulation of aldosterone is abnormal in some patients with essential hypertension. Most patients with low-renin essential hypertension have normal secretion rates and urinary excretion rates of aldosterone, despite low plasma renin activity (1-4). The secretion rate, excretion rate, and plasma levels of aldosterone do not suppress normally in response to sodium loading in patients with essential hypertension, particularly those with low plasma renin activity (5-7). Additionally, levels of plasma aldosterone of patients with low-renin essential hypertension are greater than normal after prolonged recumbency (8) and increase briskly after assumption of upright posture, despite a blunted response in plasma renin activity $(4,6)$. Thus, levels of aldosterone of some patients with essential hypertension are inappropriately high for the levels of plasma renin activity.

To determine if the dissociation of levels of aldosterone and plasma renin activity in hypertensive patients with low plasma renin activity is due to an increased adrenal responsiveness to angiotensin II, we 
compared the levels of plasma aldosterone of patients with essential hypertension with those of normal subjects during an infusion of angiotensin II and after stimulation of endogenous angiotensin by furosemide and upright posture.

The effect of angiotensin II on the metabolic clearance of aldosterone was also examined to determine if increases in levels of plasma aldosterone during the infusion of angiotensin II reflected increases in the rate of secretion of aldosterone or merely decreases in the metabolic clearance of aldosterone (9).

\section{METHODS}

\section{Subjects}

Angiotensin II was infused into 13 normal subjects and 16 patients with essential hypertension. The study was approved by the Human Studies Committee of the Mayo Clinic. Informed, written consent was obtained from all participants. Patients with accelerated or malignant hypertension, renal insufficiency, heart failure, or hepatic dysfunction were excluded. None of the subjects or patients were receiving oral contraceptives. All subjects and patients were white. 10 patients had normal-renin essential hypertension, and six patients had low-renin essential hypertension (Table I). The means of the ages and weights of the normal subjects, the patients with normal-renin essential hypertension, and patients with low-renin essential hypertension were not significantly different. Mean blood pressures of patients with normal-renin essential hypertension and low-renin essential hypertension were not significantly different. The use of antihypertensive medications was discontinued at least $2 \mathrm{wk}$ before testing. During this 2 -wk period, patients ingested diets containing ad lib amounts of sodium.

\section{Protocols}

Angiotensin II infusions. Supplemental sodium, $155 \mathrm{meq}$ daily, and dexamethasone, $2 \mathrm{mg}$ daily, were given during the 2 days before infusion of angiotensin II to minimize the influence of endogenous angiotensin II and ACTH. After a 120-min control period, angiotensin II (Hypertensin-CIBA, CIBA-Geigy Corp. Pharmaceuticals Div., Summit, N. J.) was infused at rates of $0.1,0.5,1.0$, and $2.0 \mathrm{ng} / \mathrm{kg}$ per min

TABLE I

Characteristics of Normal Subjects and Patients with Essential Hypertension Infused with Angiotensin II*

\begin{tabular}{lccc}
\hline & $\begin{array}{c}\text { Normal } \\
\text { subjects } \\
(n=13)\end{array}$ & $\begin{array}{c}\text { Normal-renin } \\
\text { essential } \\
\text { hypertension } \\
(n=10)\end{array}$ & $\begin{array}{c}\text { Low-renin } \\
\text { essential } \\
\text { hypertension } \\
(n=6)\end{array}$ \\
\hline Males & 8 & 8 & 1 \\
Females & 5 & 2 & 5 \\
$\begin{array}{l}\text { Age, yr } \\
\text { Weight, } k g\end{array}$ & $44 \pm 2.8$ & $43 \pm 3.7$ & $53 \pm 3.3$ \\
$\begin{array}{l}\text { Mean blood } \\
\text { pressure, } \mathrm{mm} \mathrm{Hg}\end{array}$ & $77.8 \pm 3.98$ & $90.4 \pm 5.72$ & $80.5 \pm 6.38$ \\
\hline
\end{tabular}

$*$ Mean \pm SE. during four sequential 30-min periods using an infusion pump (Harvard Apparatus Co., Inc., Millis, Mass.). The infusion was followed by a 30 -min control period. A blood sample was obtained just before the end of each infusion period and both control periods. Normal saline was infused to replace the volume of blood lost by sampling. Hollenberg et al. (10) demonstrated that plasma levels of angiotensin II plateaued within $3 \mathrm{~min}$ and that plasma levels of aldosterone reached stable levels within 20 min during infusion of angiotensin II at rates of $1 \mathrm{ng} / \mathrm{kg}$ per min and $10 \mathrm{ng} / \mathrm{kg}$ per min.

Stimulated plasma renin activity. Normal subjects and patients received $40 \mathrm{mg}$ of furosemide orally at 6 p.m., midnight, and 6 a.m. the next day. They were then maintained in an upright posture from 6 to 10 a.m., after which time a peripheral blood sample was obtained. At least 1 day separated the infusion of angiotensin II and the administration of furosemide. Patients with essential hypertension were classified as having low-renin essential hypertension if their plasma renin activity after this maneuver was less than the range of plasma renin activity found in a group of age-matched normal subjects tested by this method in our laboratory. The range of plasma renin activity after this maneuver in these normal subjects was $1.7-10.4 \mathrm{ng} / \mathrm{ml}$ per $\mathrm{h}$. Carey et al. (2) have demonstrated that this maneuver correctly identifies patients with low-renin essential hypertension, and Lowder and Liddle (11) subsequently have shown that this method of classifying the renin status of patients with essential hypertension gives reproducible results. Crane and Harris (12) have demonstrated that stimulated plasma renin activity of normal subjects declines with increasing age, especially in subjects over $40 \mathrm{yr}$ of age. Very low values may be present in those over $50 \mathrm{yr}$ of age. Plasma renin activity was low in 2 of the 30 normal subjects tested in our laboratory. Both subjects were over $50 \mathrm{yr}$ of age.

Aldosterone metabolic clearance during angiotensin II infusion. Aldosterone metabolic clearance was determined by the constant infusion technique of Tait et al. (13) using tritium-labeled aldosterone $\left(\left[1,2-{ }^{3} \mathrm{H}\right]\right.$ aldosterone sp act 57 $\mathrm{Ci} / \mathrm{mmol}$; New England Nuclear, Boston, Mass.) as described by Brown (4). Four patients with normal-renin essential hypertension and three patients with low-renin essential hypertension were studied. Antihypertensive medications were discontinued $2 \mathrm{wk}$ before testing, and supplemental sodium and dexamethasone were again given during the 2 days before the determination of aldosterone metabolic clearance. After a 120 -min control period, $5 \mu \mathrm{Ci}$ of tritium-labeled aldosterone was injected intravenously. $30 \mathrm{~min}$ later a constant intravenous infusion of tritium-labeled aldosterone was begun at a rate of $0.10 \mu \mathrm{Ci} / \mathrm{min}$ and continued for the remainder of the test. The metabolic clearance of aldosterone before infusion of angiotensin II was determined from samples of the infusate of tritium-labeled aldosterone and from samples of plasma taken 90,100 , and $110 \mathrm{~min}$ after the first injection of tritium-labeled aldosterone. While the constant infusion of tritium-labeled aldosterone continued, angiotensin II was then infused into a separate infusion site at a rate of $2 \mathrm{ng} / \mathrm{kg}$ per min. Two of the patients with normalrenin essential hypertension received $1 \mathrm{ng} / \mathrm{kg}$ per $\mathrm{min}$ of angiotensin II. The metabolic clearance of aldosterone during infusion of angiotensin II was determined from samples of the infusate of tritium-labeled aldosterone and from samples of plasma taken 50,60, and $70 \mathrm{~min}$ after the beginning of the infusion of angiotensin II.

Measurements. Blood pressure was measured by mercury sphygmomanometry. Mean blood pressure was calculated as the diastolic blood pressure plus one-third the pulse pressure.

Plasma aldosterone was determined by radioimmunoassay 
(14). The interassay coefficient of variation was $14 \%$. Plasma renin activity was determined by measuring the amount of angiotensin I generated in plasma during incubation at $37^{\circ} \mathrm{C}$ over $\mathrm{l}$ and $3 \mathrm{~h}$ by radioimmunoassay, as described by Haber, et al. (15), with the following modifications. Blood was collected in a chilled tube containing EDTA, centrifuged at $4^{\circ} \mathrm{C}$, and the chilled plasma was acidified to $\mathrm{pH} 5.5$ with $1 \mathrm{~N}$ hydrochloric acid. Aliquots of $0.5 \mathrm{ml}$ were then incubated at $37^{\circ} \mathrm{C}$ for 1 and $3 \mathrm{~h}$ in the presence of $1.6 \mathrm{mM}$ dimercaprol and $3.4 \mathrm{mM}$ 8-hydroxyquinoline sulfate. After incubation, the plasma was diluted with $0.5 \mathrm{ml}$ of $0.1 \mathrm{M}$ Tris buffer, $\mathrm{pH}$ 7.4 , and immersed in boiling water for 5 min. Radioimmunoassay of the angiotensin I generated was performed using the Angiotensin I Immutope Kit (E. R. Squibb and Sons, Princeton, N. J.). The generation of angiotensin I was linear with time. The interassay coefficient of variation of the radioimmunoassay was $9 \%$. Plasma fluorogenic steroids were measured by a spectrofluorometer (16). Serum potassium and sodium were measured by flame photometry. The concentrations of tritium-labeled aldosterone in samples of infusate and plasma were measured as described by Brown (4) for determination of metabolic clearance of aldosterone. Statistical differences were assessed by the rank-sum test (17).

\section{RESULTS}

Effects of angiotensin II infusion on plasma aldosterone. The levels of plasma aldosterone after sodium loading, dexamethasone treatment, and supine posture and before the infusion of angiotensin II were the same in normal subjects, patients with normalrenin essential hypertension, and patients with lowrenin essential hypertension (Fig. 1). After each dose of angiotensin II, the levels of plasma aldosterone of patients with normal-renin essential hypertension were the same as the levels of plasma aldosterone of normal subjects. In contrast, the levels of plasma aldosterone of patients with low-renin essential hypertension were significantly higher than the levels of plasma aldosterone of normal subjects or of patients
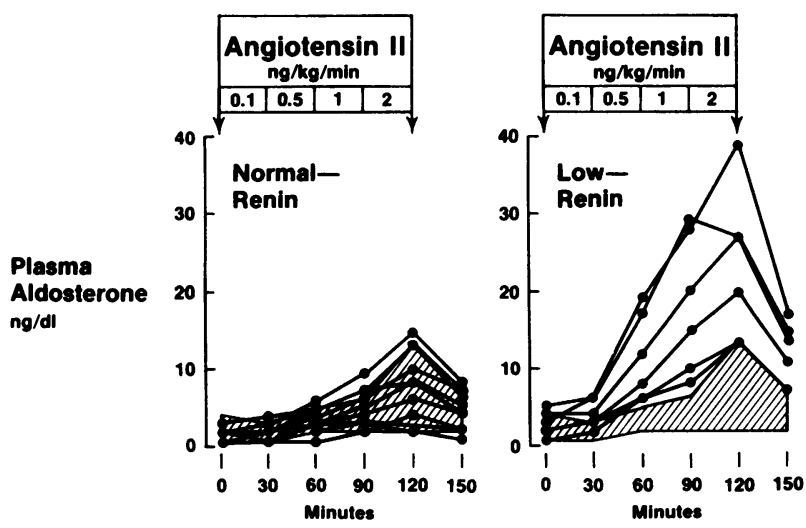

Figure 1 Effect of angiotensin II on plasma aldosterone in six patients with low-renin essential hypertension and 10 patients with normal-renin essential hypertension. Angiotensin II was infused after 2 days of supplemental sodium and dexamethasone and $2 \mathrm{~h}$ of supine posture. Hatched area shows the range of plasma aldosterone in 13 normal subjects. with normal-renin essential hypertension. The level of plasma aldosterone of each subject and patient decreased after the infusion of angiotensin II was stopped. Noteworthy is that $30 \mathrm{~min}$ after the infusion the decrease of levels of plasma aldosterone, in percentage, was the same in subjects and patients.

The levels of plasma renin activity, plasma fluorogenic steroids, and serum potassium and sodium of patients with low-renin essential hypertension and of patients with normal-renin essential hypertension were within the range of the levels in normal subjects before and during the infusion of angiotensin II (Fig. 2 ). The levels in patients with low-renin essential hypertension and normal-renin essential hypertension were not significantly different.

The mean blood pressures of patients with low-renin essential hypertension were the same as the mean blood pressures of patients with normal-renin essential hypertension before and during infusion of angiotensin II (Fig. 3). During the first $10 \mathrm{~min}$ after the infusion of angiotensin II was stopped, the decrements of mean blood pressures of normal subjects, patients with normal-renin essential hypertension, and patients with low-renin essential hypertension were the same. 30 min after the infusion was stopped, the blood pressures had not decreased further.

Effects of furosemide and upright posture on plasma aldosterone. After furosemide and upright posture, the levels of plasma aldosterone of patients with lowrenin essential hypertension were the same as the levels of plasma aldosterone of normal subjects and were significantly higher than those of patients with

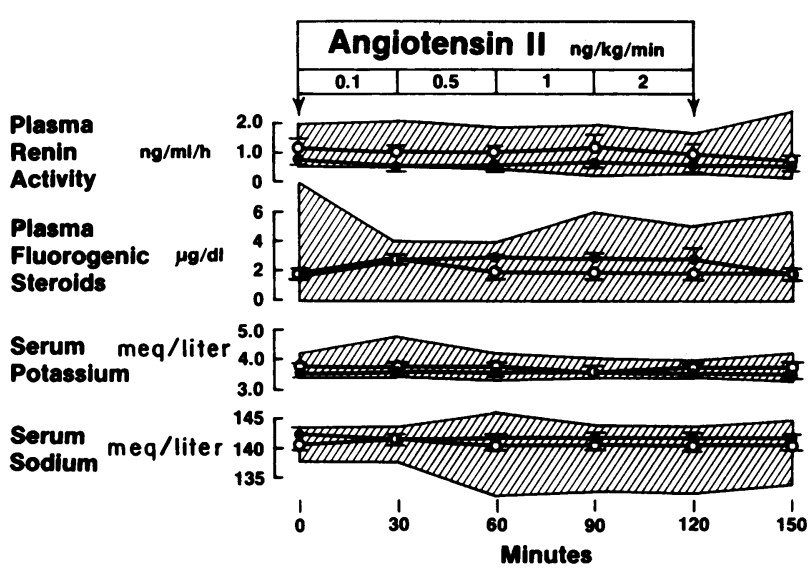

FIGURE 2 Levels of plasma renin activity, plasma fluorogenic steroids, and serum potassium and sodium during infusion of angiotensin II. Open circles represent means of levels in patients with normal-renin essential hypertension, and closed circles represent means of levels in patients with low-renin essential hypertension. Horizontal bars show the standard error. Hatched area is the range of levels in normal subjects. 

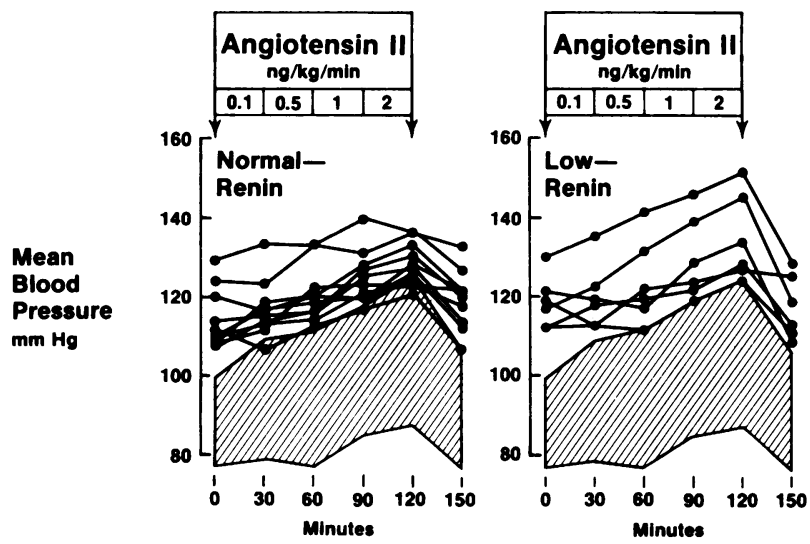

Figure 3 Mean blood pressures during infusion of angiotensin II. Mean blood pressure is the diastolic blood pressure plus one-third the pulse pressure. Hatched area shows the range of mean blood pressures of normal subjects.

normal-renin essential hypertension (Fig. 4). These normal levels of plasma aldosterone in patients with low-renin essential hypertension occurred despite the markedly blunted response of their plasma renin activity.

The percentage decrease in weight, the levels of plasma fluorogenic steroids, and serum sodium after furosemide and upright posture were not significantly different in the three groups (Table II). Levels of serum potassium after furosemide and upright posture in patients with low-renin essential hypertension were less than those in normal subjects $(P<0.02)$ and in patients with normal-renin essential hypertension.

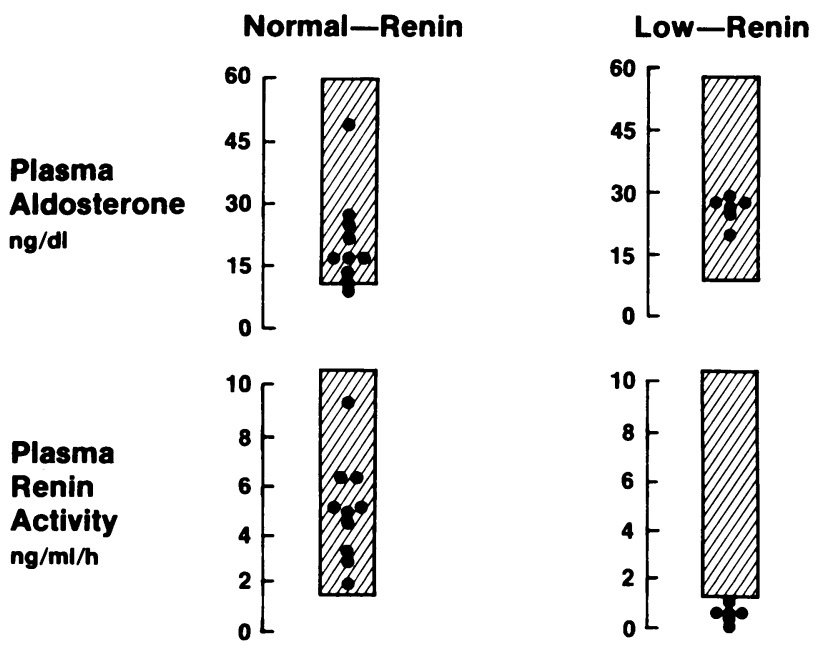

Figure 4 Effects of furosemide and upright posture on plasma aldosterone and plasma renin activity. A total of $120 \mathrm{mg}$ of furosemide was given orally in divided doses during $16 \mathrm{~h}$ before a peripheral plasma sample was obtained after $4 \mathrm{~h}$ of upright posture. Hatched area depicts the range of levels in normal subjects.
TABLE II

Decrease in Body Weight, Levels of Fluorogenic Steroids, Serum Sodium and Potassium, and Mean Blood Pressure after Furosemide and Upright Posture in Normal Subjects and Patients with Essential Hypertension*

\begin{tabular}{lccr}
\hline & $\begin{array}{c}\text { Normal } \\
\text { subjects }\end{array}$ & $\begin{array}{c}\text { Normal-renin } \\
\text { essential } \\
\text { hypertension }\end{array}$ & $\begin{array}{c}\text { Low-renin } \\
\text { essential } \\
\text { hypertension }\end{array}$ \\
\hline $\begin{array}{c}\text { Decrease in body } \\
\text { weight, \% }\end{array}$ & $3 \pm 0.3$ & $2 \pm 0.3$ & $4 \pm 0.4$ \\
$\begin{array}{c}\text { Plasma fluorogenic } \\
\text { steroids, } \mu \text { g/dl }\end{array}$ & $22 \pm 1.9$ & $16 \pm 1.8$ & $22 \pm 1.7$ \\
$\begin{array}{c}\text { Serum potassium, } \\
\text { meq/liter }\end{array}$ & $4.2 \pm 0.06$ & $4.2 \pm 0.10$ & $3.8 \pm 0.17$ \\
$\begin{array}{c}\text { Serum sodium, } \\
\text { meq/liter }\end{array}$ & $139 \pm 0.3$ & $140 \pm 0.4$ & $141 \pm 1.2$ \\
$\begin{array}{c}\text { Mean blood } \\
\text { pressure, } m m \text { Hg }\end{array}$ & $91 \pm 2.1$ & $110 \pm 3.5$ & $108 \pm 2.9$ \\
\hline
\end{tabular}

* Mean \pm SE.

Effects of angiotensin II infusion on metabolic clearance of aldosterone. The concentrations of tritiumlabeled aldosterone in the infusate and in the plasma were constant $90,100,110 \mathrm{~min}$ after beginning the infusion of tritium-labeled aldosterone and 50, 60, and $70 \mathrm{~min}$ after beginning the infusion of angiotensin II, indicating equilibrium had been obtained during determinations of aldosterone metabolic clearance. The ${ }^{14} \mathrm{C} /{ }^{3} \mathrm{H}$ ratio was not significantly altered after sequential chromatography steps before and after acetylation (4), indicating radiochemical purity of the isolated tritium-labeled aldosterone.

The metabolic clearance of aldosterone decreased during infusion of angiotensin II in all patients (Table III). The percentage decreases in metabolic clearance of aldosterone during infusion of angiotensin II were similar in patients with normal-renin essential hypertension and in patients with low-renin essential hypertension.

\section{DISCUSSION}

This study indicates that the aldosterone-secreting cells of the adrenal cortex in patients with low-renin essential hypertension are more sensitive to the stimulating effects of angiotensin than normal. This could explain the dissociation of the renin-angiotensin aldosterone axis during sodium loading (5-7), prolonged recumbency (8), and upright posture $(4,6)$ and after furosemide-induced sodium depletion, as observed in a patient reported by Bayard et al. (18) and in the patients in this study. However, other explanations need to be considered. 
TABLE III

Metabolic Clearance of Aldosterone before and during Infusion of $2 \mathrm{ng} / \mathrm{kg}$ per min Angiotensin II in Patients with Essential Hypertension

\begin{tabular}{lccc}
\hline & \multicolumn{3}{c}{ Metabolic clearance of aldosterone } \\
\cline { 2 - 4 } & $\begin{array}{c}\text { Before } \\
\text { infusion of } \\
\text { angiotensin II }\end{array}$ & $\begin{array}{c}\text { During } \\
\text { infusion of } \\
\text { angiotensin II }\end{array}$ & $\begin{array}{c}\text { Percentage } \\
\text { decrease during } \\
\text { angiotensin II } \\
\text { infusion }\end{array}$ \\
\hline liter/24 & $\mathrm{h}^{\prime} \mathrm{m}^{2}$ & \\
Normal-renin & 852 & 746 & $12^{*}$ \\
Essential & 1,007 & 873 & 13 \\
Hypertension & 1,047 & 731 & $30^{*}$ \\
Low-renin & 1,270 & 899 & 29 \\
Essential & 804 & 713 & 11 \\
Hypertension & 699 & 592 & 15 \\
\hline
\end{tabular}

* Patients received $1 \mathrm{ng} / \mathrm{kg}$ per min angiotensin II.

One explanation is a lower-than-normal metabolic clearance of angiotensin II in patients with low-renin essential hypertension. This could cause higher plasma levels of angiotensin II and thus a greater stimulus to the adrenal glands to produce aldosterone. However, the decrements of mean blood pressure after the infusion of angiotensin II was stopped were the same in patients with low-renin essential hypertension, patients with normal-renin essential hypertension, and normal subjects. Thus, equal rates of disappearance of one effect of angiotensin II in normal subjects and in patients with essential hypertension suggest that the metabolic clearance of the infused angiotensin II was not lower-than-normal in patients with lowrenin essential hypertension. More direct measurements of angiotensin II metabolism are needed to confirm this conclusion.

Another explanation is a greater-than-normal decrease in metabolic clearance of aldosterone during infusion of angiotensin II in patients with low-renin essential hypertension. This could result in higher levels of plasma aldosterone during infusion of angiotensin II in patients with low-renin essential hypertension than in patients with normal-renin essential hypertension, even though increases in secretion rates of aldosterone in response to the infusion of angiotensin II were the same in both groups. Recently, Messerli et al. (9) reported that the metabolic clearance of aldosterone in normal subjects decreased by $23 \%$ during infusion of angiotensin II at a rate of $3.0 \mathrm{ng} / \mathrm{kg}$ per min and by $37 \%$ when the rate was increased to $22 \mathrm{ng} / \mathrm{kg}$ per min. The results of the present study provide evidence that the decrease in metabolic clearance of aldosterone during infusion of angiotensin II was the same in patients with normal-remin and low-renin essential hypertension. Thus, the greater-than-normal increases in levels of plasma aldosterone during infusion of angiotensin II in patients with low-renin essential hypertension cannot be explained by decreases in metabolic clearance of aldosterone during infusion of angiotensin II.

Our observations of the effect of angiotensin II on plasma aldosterone differ from some previous reports. Mendelsohn et al. (19) infused angiotensin II into normal subjects and into patients with essential hypertension and found no difference in levels of plasma aldosterone between the two groups at the end of the infusion. However, the doses of angiotensin II were not standardized according to body weight, and the patients were not classified by plasma renin activity. Therefore, we cannot compare our results with theirs.

Kisch et al. (20) infused angiotensin II into sodiumloaded normal subjects and patients with normal-renin essential hypertension. They found that the increment in levels of plasma aldosterone after the infusion of angiotensin II at a rate of $0.3 \mathrm{ng} / \mathrm{kg}$ per min was seven times greater in the patients with normal-renin essential hypertension than in normal subjects. One explanation for the difference between the results of the present study and the results of Kisch et al. is the difference in preparation of the normal subjects and patients for infusion of angiotensin II. In the present study, dexamethasone was given for 2 days before the infusion of angiotensin II to suppress secretion of ACTH from the pituitary gland, whereas no dexamethasone was given in the study of Kisch et al. Rayyis and Horton (21) found that treatment with dexamethasone blunted the increase in levels of plasma aldosterone after angiotensin II infusion in normal subjects. Factors that might cause enhanced adrenal responsiveness to angiotensin II in patients with normal-renin essential hypertension might be altered by treatment with dexamethasone. In patients with low-renin essential hypertension, these factors might be less responsive to dexamethasone treatment.

In the present study the normal levels of plasma aldosterone in response to furosemide and upright posture in patients with low-renin essential hypertension are additional evidence of increased adrenal sensitivity to angiotensin II-in this instance, to endogenous angiotensin II. That is, the same patients who had abnormally high levels of plasma aldosterone after infusion of angiotensin II had levels of plasma aldosterone inappropriately high for their low levels of plasma renin activity after furosemide and upright posture.

Levels of serum potassium after furosemide and upright posture in patients with low-renin essential hypertension were lower than those in normal subjects and patients with normal-renin essential hypertension. Low levels of serum potassium in patients 
with low-renin essential hypertension would likely have lowered levels of plasma aldosterone in these patients $(22,23)$. Therefore, the difference in levels of serum potassium does not likely explain normal levels of plasma aldosterone after furosemide and upright posture in patients with low-renin essential hypertension.

In the present study, levels of plasma aldosterone, after sodium loading, dexamethasone treatment, and supine posture, were suppressed equally in normal subjects, patients with normal-renin essential hypertension, and patients with low-renin essential hypertension. This contrasts with a previous report (6) showing levels of plasma aldosterone in patients with essential hypertension do not suppress normally after sodium loading and supine posture. These observations suggest that when stimulation of aldosterone secretion by the renin-angiotensin system is minimal, factors responsible for inappropriately high secretion of aldosterone in patients with essential hypertension can be suppressed by treatment with dexamethasone. An alternative explanation for suppressed levels of plasma aldosterone in patients with essential hypertension after dexamethasone treatment is a greater-thannormal increase in the metabolic clearance of aldosterone in patients with essential hypertension in response to dexamethasone.

Noteworthy in this study was that an enhanced pressor response to angiotensin II was not found in the patients with low-renin essential hypertension. Thus, the adrenal cortex and not the vascular smooth muscle of these patients probably was more sensitive to the effects of angiotensin II under the conditions of this study.

The results of this study suggest that the aldosteronesecreting cells of the adrenal cortex of patients with low-renin essential hypertension are more sensitive to angiotensin II than are those of patients with normalrenin essential hypertension or normal subjects, which may explain the dissociation of aldosterone and plasma renin activity in low-renin essential hypertension.

\section{ACKNOWLEDGMENTS}

Radioimmunoassay of angiotensin I was kindly performed by Mr. David C. Manahan in the laboratory of Dr. Cameron G. Strong and Dr. J. Carlos Romero, Mayo Clinic.

\section{REFERENCES}

1. Woods, J. W., G. W. Liddle, E. G. Stant, Jr., A. M. Michelakis, and A. B. Brill. 1969. Effect of an adrenal inhibitor in hypertensive patients with suppressed renin. Arch. Intern. Med. 123: 366-370.

2. Carey, R. M., J. G. Douglas, J. R. Schweikert, and G. W. Liddle. 1972. The syndrome of essential hypertension and suppressed plasma renin activity. Arch. Intern. Med. 130: $849-854$.
3. Fishman, L. M., O. Küchel, G. W. Liddle, A. M. Michelakis, R. D. Gordon, and W. T. Chick. 1968. Incidence of primary aldosteronism uncomplicated "essential" hypertension: a prospective study with elevated aldosterone secretion and suppressed plasma renin activity used as diagnostic criteria. JAMA (J. Am. Med. Assoc.). 205: 497-502.

4. Brown, R. D. 1976. Aldosterone metabolic clearance is normal in low-renin essential hypertension. J. Clin. Endocrinol. Metab. 42: 661-666.

5. Weinberger, M. H., A. J. Dowdy, G. W. Nokes, and J. A. Luetscher. 1968. Plasma renin activity and aldosterone secretion in hypertensive patients during high and low sodium intake and administration of diuretic. J. Clin. Endocrinol. Metab. 28: 359-371.

6. Luetscher, J. A., M. H. Weinberger, A. J. Dowdy, G. W. Nokes, H. Balikian, A. Brodie, and S. Willoughby. 1969. Effects of sodium loading, sodium depletion and posture on plasma aldosterone concentration and renin activity in hypertensive patients. J. Clin. Endocrinol. Metab. 29: 1310-1318.

7. Collins, R. D., M. H. Weinberger, A. J. Dowdy, G. W. Nokes, C. M. Gonzales, and J. A. Luetscher. 1970. Abnormally sustained aldosterone secretion during salt loading in patients with various forms of benign hypertension; relation to plasma renin activity. J. Clin. Invest. 49: 1415-1426.

8. Grim, C., J. Winnacker, T. Peters, and G. Gilbert. 1974. Low renin, "normal" aldosterone and hypertension: circadian rhythm of renin, aldosterone, cortisol and growth hormone. J. Clin. Endocrinol. Metab. 39: 247256.

9. Messerli, F. H., W. Nowaczynski, M. Honda, J. Genest, R. Boucher, O. Kuchel, and J. M. Rojo-Ortega. 1977. Effects of angiotensin II on steroid metabolism and hepatic blood flow in man. Circ. Res. 40: 204-207.

10. Hollenberg, N. K., W. R. Chenitz, D. F. Adams, and G. H. Williams. 1974. Reciprocal influence of salt intake on adrenal glomerulosa and renal vascular responses to angiotensin II in normal man. J. Clin. Invest. 54: 34-42.

11. Lowder, S. C., and G. W. Liddle. 1974. Prolonged alteration of renin responsiveness after spironolactone therapy: a cause of false-negative testing for low-renin hypertension. N. Engl. J. Med. 291: 1243-1244.

12. Crane, M. G., and J. J. Harris. 1976. Effect of aging on renin activity and aldosterone excretion.J. Lab. Clin. Med. 87: 947-959.

13. Tait, J. F., B. Little, S. A. S. Tait, and C. Flood. 1962. The metabolic clearance rate of aldosterone in pregnant and nonpregnant subjects estimated by both singleinjection and constant-infusion methods. J. Clin. Invest. 41: 2093-2099.

14. McKenzie, J. K., and J. A. Clements. 1974. Simplified radioimmunoassay for serum aldosterone utilizing increased antibody specificity. J. Clin. Endocrinol. Metab. 38: 622-627.

15. Haber, E., T. Koerner, L. B. Page, B. Kliman, and A. Purnode. 1969. Application of a radioimmunoassay for angiotensin I to the physiologic measurements of plasma renin activity in normal human subjects. J. Clin. Endocrinol. Metab. 29: 1349-1355.

16. Mattingly, D. 1962. A simple fluorimetric method for the estimation of free 11-hydroxycorticoids in human plasma. J. Clin. Pathol. (Lond.). 15: 374-379.

17. Dixon, W. J., and F. J. Massey, Jr. 1969. Introduction to Statistical Analysis. McGraw-Hill Book Company, New York. 3rd edition. 344-345. 
18. Bayard, F., C. L. Alicandri, I. Z. Beitins, G. D. Lubash, A. Kowarski, and C. J. Migeon. 1971. A dynamic study of plasma renin activity and aldosterone concentration in normal and hypertensive subjects. Metab. Clin. Exp. 20: 513-519.

19. Mendelsohn, F. A. O., C. I. Johnston, A. E. Doyle, B. A. Scoggins, D. A. Denton, and J. P. Coghlan. 1972. Renin, angiotensin II, and adrenal corticosteroid relationships during sodium deprivation and angiotensin infusion in normotensive and hypertensive man. Circ. Res. 31: 728-739.

20. Kisch, E. S., R. G. Dluhy, and G. H. Williams. 1976.
Enhanced aldosterone response to angiotensin II in human hypertension. Circ. Res. 38: 502-505.

21. Rayyis, S. S., and R. Horton. 1971. Effect of angiotensin II on adrenal and pituitary function in man. J. Clin. Endocrinol. Metab. 32: 539-546.

22. Cannon, P. J., R. P. Ames, and J. H. Laragh. 1966. Relation between potassium balance and aldosterone secretion in normal subjects and in patients with hypertensive or renal tubular disease. J. Clin. Invest. 45: 865-879.

23. Himathongkam, T., R. G. Dluhy, and G. H. Williams. 1975. Potassium-aldosterone-renin interrelationships. $J$. Clin. Endocrinol. Metab. 41: 153-159. 